\title{
Synthesis and characterization of poly(multi- dimethylsiloxane-1,4-ethynylenephenyleneethynylene)s
}

\author{
Fei Gao, Farong Huang, Lemin Tang and Lei Du
}

A series of poly(multidimethylsiloxane-1,4-ethynylenephenyleneethynylene)s were synthesized by condensation reactions of 1,4 -diethynylbenzene magnesium reagents with various $\alpha, \omega$-dichlorodimethylsiloxanes. The polymers obtained were solids or viscous liquids and are soluble in common organic solvents at room temperature. The structures and properties of the polymers were characterized by Fourier transform infrared, ${ }^{1} \mathrm{H}$ nuclear magnetic resonance (NMR), ${ }^{13} \mathrm{C}$ NMR, differential scanning calorimeter (DSC), dynamic mechanical analysis (DMA) and thermogravimetric analysis (TGA) techniques. DSC analyses showed that these polymers can be thermally cured to form highly crosslinked structures. DMA studies revealed that the glass transition temperatures of the cured polymers decreased with increasing siloxane chain length. TGA measurements showed that the cured polymers were thermally stable up to almost $450{ }^{\circ} \mathrm{C}$ in both $\mathrm{N}_{2}$ and air. With increasing length of the siloxane units, the thermal stability of the cured polymers decreased. Silicon oxycarbide ceramics with high thermal stability were produced when the cured polymers were pyrolyzed at $1200^{\circ} \mathrm{C}$ under argon.

Polymer Journal (2011) 43, 136-140; doi:10.1038/pj.2010.118; published online 24 November 2010

Keywords: diethynylbenzene; organic-inorganic polymer; siloxane-diethynylbenzene polymer; SiOC ceramic; thermally stable polymer

\section{INTRODUCTION}

Polysiloxanes had been studied extensively, and some of them were already commercialized in as early as the 1940s. Because of their good thermal stability, there was increasing interest in using them as hightemperature materials. Their thermal stability stems from the strong bond energy of Si-O bonds in the polymer chains. However, the polymers were prone to depolymerization at elevated temperatures because of random chain scission. ${ }^{1}$ It had been demonstrated that the incorporation of thermally stable aromatics into the polysiloxane backbone could improve their properties, especially their thermal stability. ${ }^{2-24}$

Diacetylene units had recently been incorporated into the main chain of polysiloxanes, which improved their thermal, oxidative and elastomeric properties. ${ }^{23,24}$ The improvement was attributed to the crosslinked network structures formed during reaction by thermal or photochemical means. Diethynylbenzene resins were discovered initially in the early 1960s by Hay. ${ }^{25}$ Diethynylbenzene resins could be cured to a highly crosslinked aromatic structure by means of an addition reaction without the evolution of volatiles. The presence of diethynylenephenylene units in the backbone of the polymer provided many attractive advantages. Itoh et al. ${ }^{26}$ reported the synthesis of poly(silyleneethynylenephenyleneethynylene)s with excellent heat- and flame resistant properties. However, few polysiloxanes containing diethynylenephenylene units in the main chain had been synthesized thus far. ${ }^{27,28}$
In this paper, a series of novel poly(siloxane)s containing diethynylenephenylene units were synthesized and characterized by gel permeation chromatography (GPC), nuclear magnetic resonance (NMR), Fourier transform infrared, differential scanning calorimeter (DSC), dynamic mechanical analysis (DMA) and thermogravimetric analysis (TGA) techniques.

\section{EXPERIMENTAL PROCEDURE}

Materials

Unless otherwise noted, all syntheses were performed under an atmosphere of dry nitrogen. Hexane, tetrahydrofuran (THF), carbon tetrachloride $\left(\mathrm{CCl}_{4}\right)$, ethyl bromide, ethyl ether, dimethyldichlorosilane, palladium dichloride $\left(\mathrm{PdCl}_{2}\right)$, silica gel, magnesium powder and phosphorus pentoxide $\left(\mathrm{P}_{2} \mathrm{O}_{5}\right)$ were purchased from Sinopharm Chemical Reagent Co. Ltd. (Shanghai, China). THF was dried and deoxygenated by distillation from the flask with sodium/benzophenone. $\mathrm{CCl}_{4}$ was dried over $\mathrm{P}_{2} \mathrm{O}_{5}$ and distilled under nitrogen. Dimethyldichlorosilane and ethyl bromide were distilled before use. Dimethylchlorosilane and 1,1,3,3-tetramethyldisiloxane were used as received from Shanghai Sili Gongmao Co. Ltd. (Shanghai, China). Octamethylcyclotetrasiloxane $\left(D_{4}\right)$ was used as received from Shanghai Hua Run Chemicals Co. Ltd. (Shanghai, China). 1,1,3,3,5,5-Hexamethyltrisiloxane, 1,1,3,3,5,5,7,7-octamethyltetrasiloxane, 1,1,3,3,5,5,7,7,9,9-decamethylpentasiloxane, 1,1,3,3,5,5,7,7,9,9,11,11-dodecamethylhexasiloxane, 1,3-dichlorotetramethyldisiloxane (DCTMDS), 1,5-dichlorohexamethyltrisiloxane (DCHMTS), 1,1,3,3,5,5,7,7dichlorooctamethyltetrasiloxane (DCOMTS), 1,9-dichlorodecamethylpentasiloxane (DCDMPS) and 1,11-dichlorododecamethylhexasiloxane (DCDMHS) were prepared according to published procedures. ${ }^{29-34}$ 1,4-Diethynylbenzene

Key Laboratory for Specially Functional Polymeric Materials and Related Technology of the Ministry of Education, School of Materials Science and Engineering, East China University of Science and Technology, Shanghai, PR China

Correspondence: Professor Dr F Huang, Key Laboratory for Specially Functional Polymeric Materials and Related Technology of the Ministry of Education, School of Materials Science and Engineering, East China University of Science and Technology, 130 Meilong Road, Shanghai 200237, PR China.

E-mail: fhuanglab@ecust.edu.cn

Received 26 June 2010; revised 9 October 2010; accepted 13 October 2010; published online 24 November 2010 
was supplied by the Fine Chemical Institute of the East China University of Science and Technology and used as received without further purification.

\begin{abstract}
Measurements
${ }^{1} \mathrm{H}$ and ${ }^{13} \mathrm{C}$ NMR spectra were acquired in deuterated chloroform on a BRUKER AVANCE 500 (Bruker, Baden-Württemberg, Germany) at a proton frequency of $500 \mathrm{MHz}$ and its corresponding carbon frequency. Fourier transform infrared spectra were obtained using a Nicolet550 spectrometer (Thermo Fisher Nicolet, Madison, WI, USA). The molecular weights of the polymers were determined by GPC using a Waters GPC system equipped with a DAWN HELEOS static laser scattering detector and an Optilab Rex refractive index detector (Wyatt Technology, Santa Barbara, CA, USA). GPC was performed using THF as an eluent at a flow rate of $1 \mathrm{ml} \mathrm{min}^{-1}$. DSC analysis was performed on a NETZSCH 200 PC module (NETZSCH, Bavaria, Germany) at a heating rate of $10^{\circ} \mathrm{Cmin}^{-1}$ in a nitrogen atmosphere. DMA was performed with a PerkinElmer DMA 7e (PerkinElmer, Waltham, MA, USA). A three-point bending mode was chosen. All samples were run at a heating rate of $3{ }^{\circ} \mathrm{C} \mathrm{min}^{-1}$ and at a load frequency of $1 \mathrm{~Hz}$ from -150 to $400^{\circ} \mathrm{C}$ in an air atmosphere. The peak of $\tan \delta$ as a function of temperature was regarded as the $\mathrm{Tg}$ of the cured film. Thermogravimetric analysis was performed on a TA Instruments DMA Q800 (TA Instruments, New Castle, Germany) with a heating rate of $10{ }^{\circ} \mathrm{C} \mathrm{min}^{-1}$ under nitrogen and air.
\end{abstract}

\section{Preparation of poly(tetramethyldisiloxane-1,4-} ethynylenephenyleneethynylene)

A 250-ml round-bottomed flask was equipped with a dropping funnel, a reflux condenser, a three-way stopcock and a mechanic stirring bar. The flask was then evacuated and back-filled with dry nitrogen three times. Magnesium powder $(6.00 \mathrm{~g}, 0.25 \mathrm{~mol})$ and anhydrous THF $(100 \mathrm{ml})$ were transferred into the flask. The reaction flask was then immersed in an ice-water bath. While stirring, a solution of ethyl bromide $(23.98 \mathrm{~g}, 0.22 \mathrm{~mol})$ in $100 \mathrm{ml}$ anhydrous THF was added dropwise over the course of $40 \mathrm{~min}$. The reaction mixture became a gray-black solution. After the flask was taken out of the ice-water bath, it was heated to $45^{\circ} \mathrm{C}$ in an oil bath and kept at $45^{\circ} \mathrm{C}$ for $1 \mathrm{~h}$ with stirring, resulting in the formation of a dark solution. The reaction flask was then cooled in an ice-water bath, and a solution of 1,4-diethynylbenzene $(13.86 \mathrm{~g}, 0.11 \mathrm{~mol})$ in anhydrous THF $(100 \mathrm{ml})$ was added dropwise over the course of $40 \mathrm{~min}$. The ice-water bath was then removed, and the reaction mixture was heated to $65^{\circ} \mathrm{C}$ in an oil bath and kept at this temperature for $1 \mathrm{~h}$ with stirring. The reaction mixture was thick slurry with a white precipitate. The flask was then cooled in an ice-water bath, and a solution of DCTMDS $(14.21 \mathrm{~g}, 0.07 \mathrm{~mol})$ in anhydrous THF $(100 \mathrm{ml})$ was added dropwise over the course of $40 \mathrm{~min}$. As the addition proceeded, the white precipitate of the organic magnesium reagent gradually disappeared. After complete addition, the ice-water bath was removed and the reaction mixture was heated to $75^{\circ} \mathrm{C}$ in an oil bath. The reaction was allowed to proceed overnight at $75^{\circ} \mathrm{C}$. After cooling to room temperature, the reaction mixture was then poured into a $2 \%$ solution of hydrochloric acid $(300 \mathrm{ml}$, aqueous) at $0{ }^{\circ} \mathrm{C}$. The resulting two-phase mixture was transferred to a $500-\mathrm{ml}$ separatory funnel and extracted three times with $75 \mathrm{ml}$ each of toluene. The toluene extracts were combined and washed with deionized water until the $\mathrm{pH}$ of the washing water was neutral. The dark organic phase was poured into a round-bottomed flask and dried over anhydrous $\mathrm{Na}_{2} \mathrm{SO}_{4}$. The organic solution was filtrated and distilled by rotary evaporation to remove the solvent, leaving polymer I, a brown solid in 93\% yield. FTIR $\left(\mathrm{KBr}, \mathrm{cm}^{-1}\right): 3297(\mathrm{C} \equiv \mathrm{C}-\mathrm{H})$, $2961\left(-\mathrm{CH}_{3}\right), 2160(\mathrm{C} \equiv \mathrm{C}), 1496\left(-\mathrm{C}_{6} \mathrm{H}_{4}-\right), 1257\left(\mathrm{Si}-\mathrm{CH}_{3}\right), 1051(\mathrm{Si}-\mathrm{O}-\mathrm{Si})$, 799-843 (Si-C); ${ }^{1} \mathrm{H}$ NMR $\left(\mathrm{CDCl}_{3}\right.$, $\delta$, p.p.m. $): 0.38\left(\mathrm{Si}_{-} \mathrm{CH}_{3}\right), 3.16(\mathrm{C} \equiv \mathrm{C}-\mathrm{H})$, $7.29\left(-\mathrm{C}_{6} \mathrm{H}_{4}-\right) .{ }^{13} \mathrm{C}$ NMR $\left(\mathrm{CDCl}_{3}, \delta\right.$, p.p.m.): $2.82\left(\mathrm{Si}_{-} \mathrm{CH}_{3}\right), 79.88,83.78$ $(-\mathrm{C} \equiv \mathrm{C}-\mathrm{H}), 96.16,104.23(\mathrm{Si}-\mathrm{C} \equiv \mathrm{C}-), 123.71,132.46\left(-\mathrm{C}_{6} \mathrm{H}_{4}-\right)$.

Polymers II-IV were prepared in a synthesis procedure similar to that of polymer I, except for the use of raw materials DCHMTS, DCOMTS, DCDMPS, and DCDMHS instead of DCTMDS during the syntheses.

Polymer II was obtained in $91 \%$ yield as a brown, viscous liquid. FTIR ( $\mathrm{KBr}$, $\left.\mathrm{cm}^{-1}\right): 3296(\mathrm{C} \equiv \mathrm{C}-\mathrm{H}), 2961\left(-\mathrm{CH}_{3}\right), 2160(\mathrm{C} \equiv \mathrm{C}), 1496\left(-\mathrm{C}_{6} \mathrm{H}_{4}-\right), 1257(\mathrm{Si}-$ $\left.\mathrm{CH}_{3}\right), 1051$ ( $\left.\mathrm{Si}-\mathrm{O}-\mathrm{Si}\right), 799-843(\mathrm{Si}-\mathrm{C}) ;{ }^{1} \mathrm{H}$ NMR $\left(\mathrm{CDCl}_{3}, \delta\right.$, p.p.m.): 0.17-0.38 $\left(\mathrm{Si}-\mathrm{CH}_{3}\right), 3.07(\mathrm{C} \equiv \mathrm{C}-\mathrm{H}), 7.29\left(-\mathrm{C}_{6} \mathrm{H}_{4}-\right) .{ }^{13} \mathrm{C} \mathrm{NMR}\left(\mathrm{CDCl}_{3}, \delta\right.$, p.p.m.): 1.74, $2.86\left(\mathrm{Si}-\mathrm{CH}_{3}\right), 79.81,83.82(-\mathrm{C} \equiv \mathrm{C}-\mathrm{H}), 96.35,103.95$ ( $\left.\mathrm{Si}-\mathrm{C} \equiv \mathrm{C}-\right), 123.75$, $132.45\left(-\mathrm{C}_{6} \mathrm{H}_{4}-\right)$.
Polymer III was obtained in $92 \%$ yield as an orange viscous liquid. FTIR $\left(\mathrm{KBr}, \mathrm{cm}^{-1}\right): 3294(\mathrm{C} \equiv \mathrm{C}-\mathrm{H}), 2960\left(-\mathrm{CH}_{3}\right), 2160(\mathrm{C} \equiv \mathrm{C}), 1498\left(-\mathrm{C}_{6} \mathrm{H}_{4}-\right), 1256$ $\left(\mathrm{Si}-\mathrm{CH}_{3}\right), 1083$ ( $\left.\mathrm{Si}-\mathrm{O}-\mathrm{Si}\right), 799-844(\mathrm{Si}-\mathrm{C}) ;{ }^{1} \mathrm{H}$ NMR $\left(\mathrm{CDCl}_{3}, \delta\right.$, p.p.m.): $0.08-$ $0.37\left(\mathrm{Si}-\mathrm{CH}_{3}\right), 3.09(\mathrm{C} \equiv \mathrm{C}-\mathrm{H}), 7.29\left(-\mathrm{C}_{6} \mathrm{H}_{4}-\right) .{ }^{13} \mathrm{C} \mathrm{NMR}\left(\mathrm{CDCl}_{3}, \delta\right.$, p.p.m.): $1.73,2.82\left(\mathrm{Si}-\mathrm{CH}_{3}\right), 77.9,83.2(-\mathrm{C} \equiv \mathrm{C}-\mathrm{H}), 96.38,104.25$ ( $\left.\mathrm{Si}-\mathrm{C} \equiv \mathrm{C}-\right), 123.73$, $132.44\left(-\mathrm{C}_{6} \mathrm{H}_{4}-\right)$.

Polymer IV was obtained in $90 \%$ yield as an orange liquid. FTIR ( $\mathrm{KBr}$, $\left.\mathrm{cm}^{-1}\right): 3299(\mathrm{C} \equiv \mathrm{C}-\mathrm{H}), 2962\left(-\mathrm{CH}_{3}\right), 2160(\mathrm{C} \equiv \mathrm{C}), 1497\left(-\mathrm{C}_{6} \mathrm{H}_{4}-\right), 1259(\mathrm{Si}-$ $\mathrm{CH}_{3}$ ), $1030-1100$ (Si-O-Si), 778-842 (Si-C); ${ }^{1} \mathrm{H}$ NMR $\left(\mathrm{CDCl}_{3}, \delta\right.$, p.p.m.): $0.35-0.40\left(\mathrm{Si}-\mathrm{CH}_{3}\right), 3.19(\mathrm{C} \equiv \mathrm{C}-\mathrm{H}), 7.39\left(-\mathrm{C}_{6} \mathrm{H}_{4}-\right) .{ }^{13} \mathrm{C}$ NMR $\left(\mathrm{CDCl}_{3}, \delta\right.$, p.p.m.): 1.74, $2.85\left(\mathrm{Si}-\mathrm{CH}_{3}\right), 79.80,83.82(-\mathrm{C} \equiv \mathrm{C}-\mathrm{H}), 96.38,104.25$ ( $\mathrm{Si}-\mathrm{C} \equiv \mathrm{C}-$ ), $123.73,132.44\left(-\mathrm{C}_{6} \mathrm{H}_{4}-\right)$.

Polymer V was obtained in $90 \%$ yield as an orange liquid. FTIR $\left(\mathrm{KBr}, \mathrm{cm}^{-1}\right)$ : $3303(\mathrm{C} \equiv \mathrm{C}-\mathrm{H}), 2963\left(-\mathrm{CH}_{3}\right), 2162(\mathrm{C} \equiv \mathrm{C}), 1496\left(-\mathrm{C}_{6} \mathrm{H}_{4}-\right), 1260\left(\mathrm{Si}-\mathrm{CH}_{3}\right), 1035-$ 1100 (Si-O-Si), 800-842 (Si-C); ${ }^{1} \mathrm{H}$ NMR $\left(\mathrm{CDCl}_{3}, \delta\right.$, p.p.m.): 0.18-0.24 ( $\left.\mathrm{Si}^{-\mathrm{CH}_{3}}\right)$, $3.03(\mathrm{C} \equiv \mathrm{C}-\mathrm{H}), 7.29\left(-\mathrm{C}_{6} \mathrm{H}_{4}-\right) .{ }^{13} \mathrm{C}$ NMR $\left(\mathrm{CDCl}_{3}, \delta\right.$, p.p.m.): 1.75, $2.86\left(\mathrm{Si}_{-} \mathrm{CH}_{3}\right)$, $79.81,83.83(-\mathrm{C} \equiv \mathrm{C}-\mathrm{H}), 96.39,103.86(\mathrm{Si}-\mathrm{C} \equiv \mathrm{C}-), 123.78,132.62\left(-\mathrm{C}_{6} \mathrm{H}_{4}-\right)$.

\section{Preparation of cured polymers}

Before curing, polymers I-V were degassed at $100^{\circ} \mathrm{C}$ per $15 \mathrm{~mm} \mathrm{Hg}$. Polymers $\mathrm{I}-\mathrm{V}$ were thermally cured by maintaining for $2 \mathrm{~h}$ at $150^{\circ} \mathrm{C}$, for $2 \mathrm{~h}$ at $170^{\circ} \mathrm{C}, 2 \mathrm{~h}$ at $210^{\circ} \mathrm{C}, 2 \mathrm{~h}$ at $250^{\circ} \mathrm{C}$ and $2 \mathrm{~h}$ at $300^{\circ} \mathrm{C}$, respectively. Thereafter, the cured polymers were allowed to cool slowly to room temperature. Shiny and void-free cured polymers $I_{c}-V_{c}$ were obtained.

\section{Thermal sinter of the cured polymers}

Cured polymers $\mathrm{I}_{\mathrm{c}}-\mathrm{V}_{\mathrm{c}}$ were weighed in an alumina crucible and placed into the tube furnace. After three purges of argon, cured polymers $I_{c}-V_{c}$ were heated at a heating rate of $2{ }^{\circ} \mathrm{C} \mathrm{min}^{-1}$ under argon according to the following procedure: $2 \mathrm{~h}$ each at $400,600,800,1000$ and $1200^{\circ} \mathrm{C}$, followed by cooling to room temperature. Hard and black products $\mathrm{I}_{\mathrm{cc}}-\mathrm{V}_{\mathrm{cc}}$ were obtained, and the products were similar to the sintered ceramics of homolog polymers that had been recognized as SiOC ceramics. ${ }^{35}$

\section{RESULTS AND DISCUSSION}

\section{Synthesis and characterization of polymers}

Polymers I-V were prepared as shown in Scheme 1. The starting compound, 1,4-diethynylbenzene, could be directly and quantitatively converted to derivatives by reaction with two equivalents of ethylmagnesium bromide in THF, and then the bismagnesium reagent reaction with various $\alpha, \omega$-dichlorodimethylsiloxanes yielded the desired copolymers. Polymers I-V were brown solids or viscous liquids and soluble in common organic solvents such as THF, acetone, butanone, dimethylformamide, chloroform and aromatic solvents, such as benzene and toluene. However, they were slightly soluble in saturated hydrocarbons and insoluble in alcohol at room temperature. The results indicated that polymers I-V had good solubility, probably because of the effect of the siloxane unit in the polymer backbone.

The number-average molecular weight of polymers I-V was between 1390 and 2100, and the polydispersity index was between 1.90 and 2.40. The average degree of polymerization of these polymers was close to each other.

Polymers I-V were characterized by infrared, ${ }^{1} \mathrm{H}$ - and ${ }^{13} \mathrm{C}$ NMR spectroscopy. The prominent absorptions exhibited by the polymers (I-V) include peaks at $3300 \mathrm{~cm}^{-1}(-\mathrm{C} \equiv \mathrm{C}-\mathrm{H}), 2963 \mathrm{~cm}^{-1}(\mathrm{C}-\mathrm{H})$, $2160 \mathrm{~cm}^{-1} \quad$ (-C $\left.\equiv \mathrm{C}-\right), \quad 1600-1400 \mathrm{~cm}^{-1}$ (aromatic rings), 1100 $1030 \mathrm{~cm}^{-1}$ (strong Si-O-Si stretching) and 1260,842 and $799 \mathrm{~cm}^{-1}$ (strong Si-C deformation). ${ }^{13} \mathrm{C}$ NMR confirmed phenylene carbons by peak resonances with chemical shifts at 123.7 and 132.6 p.p.m. The ethynyl carbon adjacent to the silicon atom was identified by peak resonances in the 96.0-97.0 p.p.m. region, and the ethynyl carbon bonded to the phenylene group was identified by peak resonances in the 103.0-104.0 p.p.m. region. The terminal ethynyl carbons appeared 


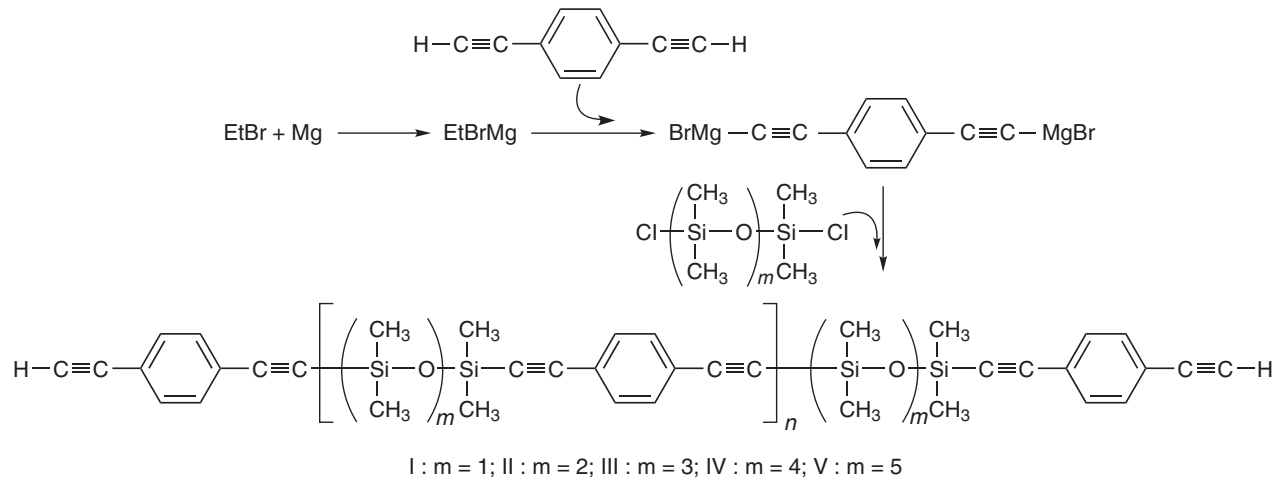

Scheme 1 Synthesis of polymers I-V.

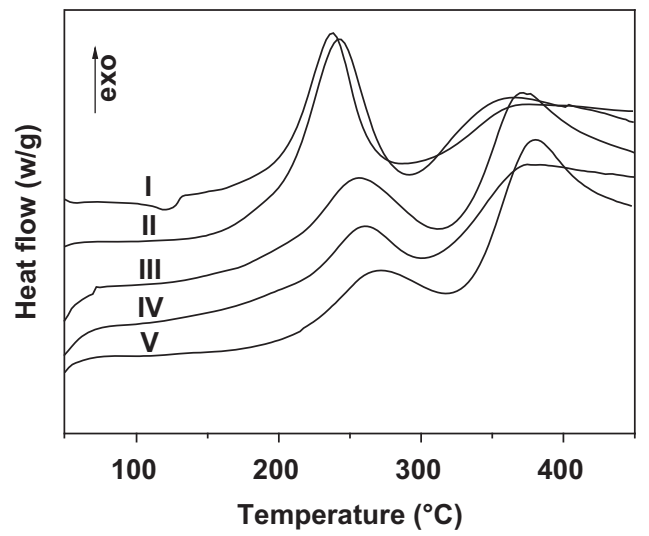

Figure 1 Differential scanning calorimeter curves of polymers I-V.

as a pair of peak resonances at 79.8 and 83.8 p.p.m. In addition, silylmethyl carbons were observed by peak resonances in the 0-2 p.p.m. region. The ${ }^{1} \mathrm{H}$ NMR spectra for polymers $\mathrm{I}-\mathrm{V}$ showed the methyl protons of siloxane resonance in the $0.4-0.0$ p.p.m. region, and the phenylene protons resonance in the 7.29-7.39 p.p.m. region. The ethynyl protons appeared in the 3.01-3.16 p.p.m. region.

\section{Thermal curing behavior of the polymers}

The thermal curing behavior of polymers I-V was investigated by DSC. The DSC curves of these polymers are shown in Figure 1. Two exothermic peaks during the heating were observed in the 150-325 and $330-450{ }^{\circ} \mathrm{C}$ ranges. The former peaks were due to the thermal polymerization of primary ethynyl groups, and the latter peaks were due to addition polymerization of internal ethynyl groups. Apparently, primary ethynyl groups could be cured at a lower temperature than internal ethynyl groups. The former peaks shifted to a higher temperature, and the latter peaks gradually became the main exothermic peak with increasing siloxane chain length, indicating the requirement of a higher temperature for reactions of the internal ethynyl units for polymers with long siloxane chain lengths due to the dilution of primary and internal ethynyl groups with increasing siloxane chain length. The thermal curing of polymers I-V was believed to proceed by an addition reaction between ethynyl groups to generate a polyene network. Theoretical simulation calculations of bond energies suggested a predominately polyene structure for the thermal polymerization of acetylene compounds. ${ }^{36,37}$ Other reactions were also possible, such as the Glasser reaction, Straus reaction, trimerization and Diels-Alder reaction. ${ }^{38}$

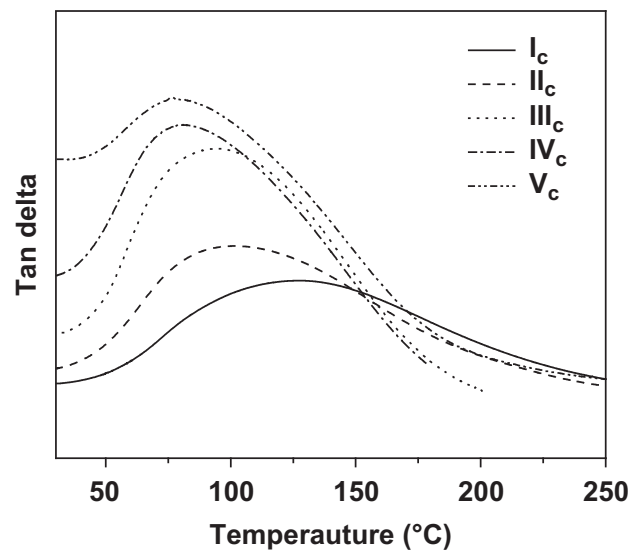

Figure $2 \operatorname{Tan} \delta$ curve from dynamic mechanical analysis of the cured polymers $\mathrm{I}_{\mathrm{c}}-\mathrm{V}_{\mathrm{c}}$.

\section{Thermomechanical properties of the cured polymers}

The thermomechanical properties of cured polymers $I_{c}-V_{c}$ were investigated by DMA under air. The DMA curves of the cured polymers are shown in Figure 2. The glass transition temperatures of cured polymers $\mathrm{I}_{\mathrm{c}}-\mathrm{V}_{\mathrm{c}}$ were $126,104,96,84$ and $78^{\circ} \mathrm{C}$, as determined by the peak temperature of the loss tangent curve. With increasing siloxane chain length, the $T_{\mathrm{g}}$ of the cured polymers decreased. On one hand, the increase in the siloxane chain length resulted in a decrease in crosslinking density. As the siloxane chain length became longer, the crosslinked density of the cured polymer decreased. By varying the length of the silarylene-siloxane chain, the crosslinking density could be controlled, as demonstrated in the reports by Keller and co-workers. ${ }^{39,40}$ On the other hand, the increase in the siloxane chain length enhanced the flexibility of the main chain of the polymer. Therefore, the glass transition temperature of the cured polymers clearly decreased with the siloxane chain length.

Thermal and thermooxidative stability of the cured polymers The thermal stability of cured polymers $I_{c}-V_{c}$ was investigated by TGA under nitrogen. The TGA curves are shown in Figure 3. The decomposition temperature at $5 \%$ weight loss $\left(T_{\mathrm{d} 5}\right)$ and the residue yields at $1000^{\circ} \mathrm{C}$ are shown in Table 1 . With increasing siloxane chain length, the decomposition temperatures at $5 \%$ weight loss $\left(T_{\mathrm{d} 5}\right)$ shifted to a lower temperature, and the residue yields also decreased. It appeared that the thermal stability decreased with increasing siloxane chain length, which correlated with the crosslinked density of the cured polymers and the thermal stability of polysiloxane. The bonds $\mathrm{Si}-\mathrm{O}-\mathrm{Si}$ 


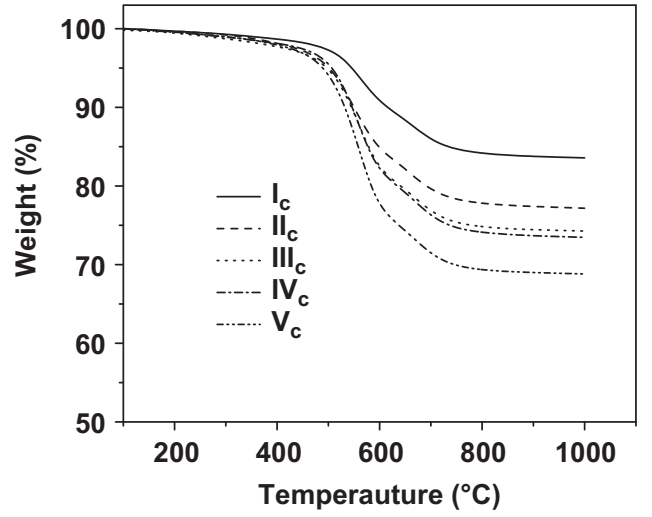

Figure 3 Thermogravimetric analysis curves of the cured polymers $I_{c}-V_{c}$ under nitrogen.

Table 1 TGA data of the cured polymers $\left(\mathrm{I}_{\mathrm{c}}-\mathrm{V}_{\mathrm{c}}\right)$

\begin{tabular}{lccccc}
\hline & \multicolumn{2}{c}{$\mathrm{T}_{d 5}\left({ }^{\circ} \mathrm{C}\right)$} & & \multicolumn{2}{c}{ Residue yield at $1000^{\circ} \mathrm{C}(\%)$} \\
\cline { 2 - 3 } \cline { 6 - 6 } Cured polymer & $N_{2}$ & Air & & $N_{2}$ & Air \\
\hline $\mathrm{I}_{\mathrm{c}}$ & 546 & 462 & & 83.2 & 39.2 \\
$\mathrm{II}_{\mathrm{C}}$ & 502 & 429 & & 76.7 & 43.7 \\
$\mathrm{III}_{\mathrm{C}}$ & 497 & 419 & & 74.3 & 43.9 \\
$\mathrm{IV}_{\mathrm{c}}$ & 495 & 417 & & 72.9 & 48.3 \\
$\mathrm{~V}_{\mathrm{c}}$ & 489 & 407 & & 68.8 & 49.3 \\
\hline
\end{tabular}

Abbreviation: TGA, thermogravimetric analysis.

in the siloxane units of the cured polymers were possibly broken, presumably by intramolecular depolymerization or by the recyclization of the siloxane chain, which was consistent with reports that increasing the siloxane chain length decreased the thermal stability of cured siloxane-containing polymers. ${ }^{41}$

The thermooxidative stability of cured polymers $\mathrm{I}_{\mathrm{c}}-\mathrm{V}_{\mathrm{c}}$ was determined by TGA under air. The TGA curves are shown in Figure 4 . The decomposition temperatures at $5 \%$ weight loss $\left(T_{\mathrm{d} 5}\right)$ and the residue yields at $1000^{\circ} \mathrm{C}$ are shown in Table 1 . The cured polymers decomposed at a lower temperature under air than under nitrogen. With increasing siloxane chain length, the decomposition temperatures at $5 \%$ weight loss $\left(T_{\mathrm{d} 5}\right)$ decreased. As the siloxane chain length increased, the residue yields at $1000{ }^{\circ} \mathrm{C}$ increased. Other siloxane-containing polymers showed similar improvements in thermooxidative stability. ${ }^{42}$ One possible explanation was the formation of $\mathrm{SiO}_{2}$ during the thermal decomposition of the cured polymers under air. ${ }^{43}$ In addition, as shown in Figure 4, there was a small peak for some weight gain around $400{ }^{\circ} \mathrm{C}$ on a TGA curve before the start of the degradation, and the increment greatly decreased with increasing siloxane chain length for the cured polymers. This trend was probably due to the oxidation reactions of the polymers. Oxygen reacted with polymers, and the weight increased. Thereafter, the oxidative polymers degraded easily. As compared with cured polymer $I_{\mathcal{C}}$, the weight-gain peak of cured polymer $\mathrm{II}_{\mathrm{c}}$ was much smaller. Therefore, the cured polymers with siloxane units had good thermal oxidative stability, but the cured polymers from ethynyl polymers exhibited poor oxidation stability.

Thermooxidative stability of the silicon oxycarbide (SiOC) ceramics The SiOC ceramics obtained from cured polymers $\mathrm{I}_{\mathrm{C}}-\mathrm{V}_{\mathrm{c}}$ pyrolyzed at $1200^{\circ} \mathrm{C}$ under argon. The ceramic yields of the cured polymers were

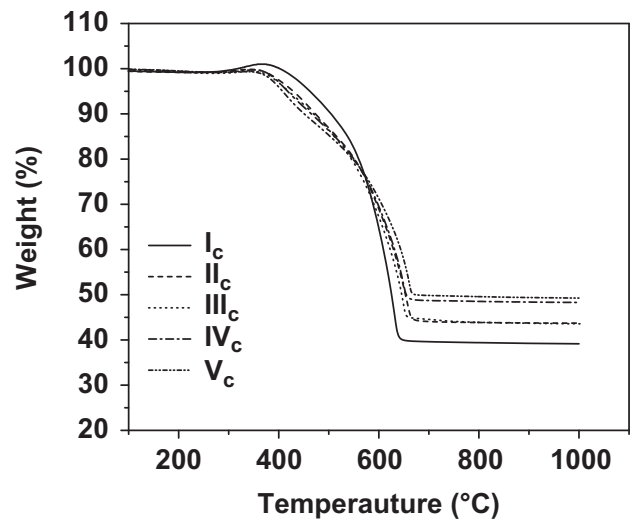

Figure 4 Thermogravimetric analysis curves of the cured polymers $I_{C}-V_{C}$ under air.

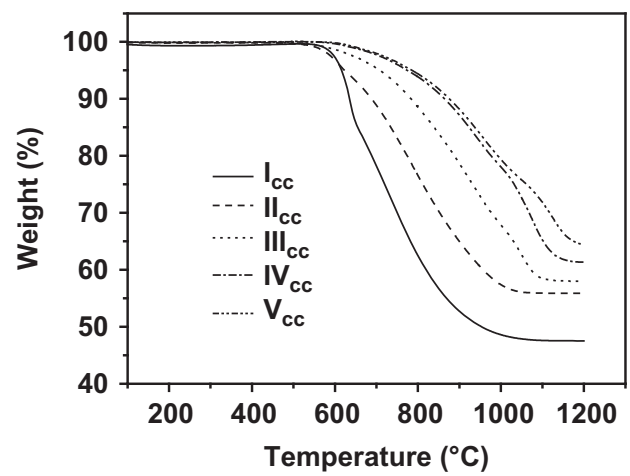

Figure 5 Thermogravimetric analysis curves of silicon oxycarbide ceramics $\mathrm{I}_{\mathrm{cc}}-\mathrm{V}_{\mathrm{cc}}$ under air.

Table 2 TGA data of the ceramics $\left(\mathrm{I}_{\mathrm{cc}}-\mathrm{V}_{\mathrm{cc}}\right)$ in air

\begin{tabular}{lcc}
\hline Ceramic & $\mathrm{T}_{d 5}\left({ }^{\circ} \mathrm{C}\right)$ & Residue yield at $1000^{\circ} \mathrm{C}(\%)$ \\
\hline $\mathrm{I}_{\mathrm{cc}}$ & 616 & 47.5 \\
$\mathrm{II}_{\mathrm{cc}}$ & 635 & 55.6 \\
$\mathrm{II}_{\mathrm{cC}}$ & 708 & 58.0 \\
$\mathrm{IV}_{\mathrm{cC}}$ & 773 & 61.3 \\
$\mathrm{~V}_{\mathrm{cc}}$ & 785 & 64.3 \\
\hline
\end{tabular}

Abbreviation: TGA, thermogravimetric analysis.

$88.08,87.20,86.60,86.51$ and $86.34 \%$. These results illustrated that the polymers were excellent precursors to SiOC ceramics. The thermooxidative stability of the SiOC ceramics was investigated by TGA in air up to $1200^{\circ} \mathrm{C}$. The TGA curves are shown in Figure 5. The decomposition temperature at $5 \%$ weight loss $\left(T_{\mathrm{d} 5}\right)$ and the residue yields at $1200^{\circ} \mathrm{C}$ are shown in Table 2 . With increasing siloxane chain length, both the decomposition temperature at $5 \%$ weight loss $\left(T_{\mathrm{d} 5}\right)$ and the residue yields of the SiOC ceramics at $1200^{\circ} \mathrm{C}$ increased. As the siloxane chain length increased, the free carbon content in the SiOC ceramic decreased. Furthermore, the formation of oxides on the surface presumably prevented the further access of air to the free carbon inside the SiOC ceramic because of surface oxidation. This result revealed that thermooxidative stability increased with increasing siloxane chain length. 


\section{CONCLUSIONS}

A series of poly(multidimethylsiloxane-1,4-ethynylenephenyleneethynylene)s were synthesized and characterized. The resulting polymers were solids or viscous liquids and soluble in common organic solvents at room temperature. At elevated temperatures, these polymers could be thermally transformed into highly crosslinked structures. The glass transition temperatures of the cured polymers decreased from 126 to $78^{\circ} \mathrm{C}$ with increasing siloxane chain length. The TGA results showed that the cured polymers had high thermal and thermooxidative stability. When the length of siloxane units was increased, the decomposition temperatures at $5 \%$ weight loss for the cured polymers decreased from 546 to $489^{\circ} \mathrm{C}$, and the residue yields at $1000{ }^{\circ} \mathrm{C}$ decreased from 83.2 to $68.8 \%$ in $\mathrm{N}_{2}$. In contrast, the decomposition temperatures at $5 \%$ weight loss for the cured polymers decreased from 462 to $407^{\circ} \mathrm{C}$, and the reside yields at $1000{ }^{\circ} \mathrm{C}$ increased from 39.2 to $49.3 \%$ in air. When the cured polymers were heated above $1200^{\circ} \mathrm{C}$ under argon, the SiOC ceramics obtained exhibited good thermoxidative stability. With increasing siloxane chain length, the decomposition temperature at $5 \%$ weight loss $\left(T_{\mathrm{d} 5}\right)$ increased from 616 to $785^{\circ} \mathrm{C}$, and the residue yields at $1200^{\circ} \mathrm{C}$ of the SiOC ceramics increased from 47.5 to $64.3 \%$.

\section{ACKNOWLEDGEMENTS}

We gratefully acknowledge the financial support from the National High Technology Research and Development Program of China (Grant No. 2002305205) and from the National Basic Research Program of China (Grant No. 18020006).

1 Thomas, T. H. \& Kendrick, T. C. Thermal analysis of polydimethylsiloxanes. I. Thermal degradation in controlled atmospheres. J. Polym. Sci. Part A-2 Polym. Phys. 7, 537-549 (1969).

2 Merker, R. L. \& Scott, M. J. Preparation and properties of poly(tetramethyl-p-silphenylene-siloxane). J. Polym. Sci. Part A General Paper 2, 15-29 (1964).

3 Patterson, W. J. \& Morris, D. E. Polymerizable siloxane precursors having in-chain perfluoroalkyl groups. J. Polym. Sci. Part A1 Polym. Chem. 10, 169-178 (1972).

4 Nagase, Y., Nakamura, T., Misawa, A., Ikeda, K. \& Sekine, Y. Thermal and mechanical properties of tetramethyl-p-silphenylenesiloxane/dimethylsiloxae block copolymer. Polymer 84, 457-462 (1983).

5 Nagase, Y., Ochiai, J., Matsui, K. \& Uchikura, M. Synthesis and gas permeability of poly(tetramethyl-p-silphenylenesiloxane)/polydialkylsiloxane) block copolymers containing fluoroalkyl substituents. Polymer 29, 740-745 (1988).

6 Dvornic, P. R. \& Lenz, R. W. Exactly alternating silarylene-siloxane polymers. 10. Synthesis and characterization of silphenylene-siloxane polymers containing fluoroalkyl and hydrido side groups. Macromolecules 27, 5833-5838 (1994).

7 Zhang, R., Pinhas, A. R. \& Mark, J. E. Synthesis of poly(tetramethyl-m-silphenylenesiloxane): an elastomer of enhanced high-temperature stability. Macromolecules $\mathbf{3 0}$, 2513-2515 (1997)

8 Li, Y. \& Kawakami, Y. Catalytic cross-dehydrocoupling polymerization of 1,4-bis(dimethylsilyl)benzene with water. A new approach to poly[(oxydimethylsilylene)(1,4phenylene)(dimethylsilylene)]. Macromolecules 32, 3540-3542 (1999).

$9 \mathrm{Li}, \mathrm{Y}$. \& Kawakami, Y. Synthesis and properties of polymers containing silphenylene moiety via catalytic cross-dehydrocoupling polymerization of 1,4-bis(dimethylsilyl)benzene. Macromolecules 32, 8768-8773 (1999).

10 Lauter, U., Kantor, S. W., Schmidt-Rohr, K. \& MacKnight, W. J. Vinyl-substituted silphenylene siloxane sopolymers: novel high-temperature elastomers. Macromolecules 32, 3426-3431 (1999).

11 Zhang, R., Mark, J. E. \& Pinhas, A. R. Dehydrocoupling polymerization of bis-silanes and disilanols to poly(silphenylenesiloxane) as catalyzed by rhodium complexes. Macromolecules 33, 3508-3510 (2000).

12 Kawakita, $\mathrm{T}$, Oh, $\mathrm{H}$, Moon, J. Y Liu, Y Imae I \& Kawakami, Y Synthesis, characterization and thermal properties of phenylene-disiloxane polymers obtained from catalytic cross-dehydrocoupling polymerization of bis(dimethylsilyl)benzene isomers and water. Polym. Int. 50, 1346-1351 (2001).

$13 \mathrm{Li}$, Y., Imae, I. \& Kawakami, Y. Novel thermally resistant polysilphenylenesiloxanes with a high content of vinyl substituents. Polym. Int. 53, 1259-1265 (2004).
14 Otomo, Y., Nagase, Y. \& Nemoto, N. Synthesis and properties of novel poly(tetramethylsilnaphthylenesiloxane) derivatives. Polymer 46, 9714-9724 (2005).

15 Rubinsztajn, S. \& Cella, J. A. A new polycondensation process for the preparation of polysiloxane copolymers. Macromolecules 38, 1061-1063 (2005).

16 Ito, H., Akiyama, E., Nagase, Y., Yamamoto, A. \& Fukui, S. Synthesis and thermal properties of fully aromatic polysilarylenesiloxanes. Polym. J. 38, 109-116 (2006).

17 Ito, H., Akiyama, E., Nagase, Y., Yamamoto, A. \& Fukui, S. Preparation of fully aromatic polysilarylenesiloxanes by melt polycondensation and their thermal properties. Polym. J. 38, 1068-1073 (2006).

18 Xue, L. \& Kawakami, Y. Precise synthesis of poly(silphenylenesiloxane)s with epoxy side functional groups by tris(pentafluorophenyl)borane as a catalyst. Polym. J. 39, 379-388 (2007)

19 Ito, H., Akiyama, E., Nagase, Y. \& Fukui, S. Syntheses of poly[(tetraphenyl-p-silphenylenesiloxane)-co-(tetramethyl-p-silphenylenesiloxane)]s and the physical properties of their films. Polym. J. 39, 471-477 (2007).

20 Maehara, T., Ohshita, J., Taketsugu, R., Hino, K. \& Kunai, A. Hydrosilylation polymerization for the synthesis of organosilicon polymers containing adamantane units. Polym. J. 41, 973-977 (2009).

21 Niwa, Y., Kouno, S., Sayama, Y. \& Nemoto, N. Synthesis and thermal characterization of novel poly(tetramethyl-1,3-silphenylenesiloxane) derivative with phenol moiety in the main chain. J. Polym. Sci. Part A Polym. Chem. 46, 692-701 (2008).

22 Hattori, Y., Miyajima, T., Sakai, M., Nagase, Y. \& Nemoto, N. Synthesis and thermal characterization of novel adamantane-based polysiloxane. Polymer 49, 2825-2831 (2008).

23 Son, D. Y. \& Keller, T. M. Synthesis and characterization of linear siloxane-diacetylene polymers. Macromolecules 28, 399-400 (1995).

24 Beckham, H. \& Keller, T. M. Diacetylene-terminated diacetylene-containing polysiloxanes. J. Mater. Chem. 12, 3363-3365 (2002).

25 Hay, A. S. Preparation of $m$ - and p-diethynyl benzenes. J. Org. Chem. 25, 637-638 (1960).

26 Itoh, M., Mitsuzuka, M., Iwata, K. \& Inoue, K. A novel synthesis and extremely high thermal stability of poly [(phenylsilylene)-ethynylene-I,3-phenyleneethynylene]. Macromolecules 27, 7917-7919 (1994).

27 Inoue, K., Iwata, K., Ishikawa, J. \& Itoh, M. Siloxane polymer and its production. J.P. 08333458 (1996)

28 Guida-Pietrasanta, F. \& Boutevin, B. Polysilalkylene or silarylene siloxanes said hybrid silicones. Adv. Polym. Sci. 179, 1-27 (2005).

29 Mirskov, R. G., Rakhlin, V. I., Voronkov, M. G. \& Gendin, D. V. Synthesis of 1,1,5,5tetramethyl-3,3-diorganyltrisiloxanes. Russ. J. Gen. Chem. 73, 165 (2003).

30 Teng, C. J., Weber, W. P. \& Cai, G. Anionic and cationic ring-opening polymerization of 2,2,4,4,6,6-hexamethyl-8,8-divinylcyclotetrasiloxane. Macromolecules $\mathbf{3 6}$, 5126-5130 (2003)

31 Beckmann, J., Dakternieks, D., Duthie, A. \& Foitizik, R. C. The use of pearlman's catalyst for the oxidation of $\mathrm{Si}-\mathrm{H}$ bonds. Synthesis, structures and acid-catalysed condensation of novel $\alpha, \omega$-oligosiloxanediols $\mathrm{HOSiMe}_{2} \mathrm{O}\left(\mathrm{SiPh}_{2}\right)_{n} \mathrm{Si}-\mathrm{Me}_{2} \mathrm{OH}(n=1-4)$. Silicon. Chem. 2, 27-36 (2003).

32 Yoshino, K., Kawamata, A., Uchida, H. \& Kabe, Y. A convenient synthesis of $\alpha, \omega$ difunctionalized linear dimethylsiloxanes with definite chain lengths. Chem. Lett. 2133-2136 (1990)

33 Uchida, H., Kabe, Y., Yoshino, K., Kawamata, A., Tsumuraya, T. \& Masamune, S. General strategy for the systematic synthesis of oligosiloxanes. Silicon dendrimers. J. Am. Chem. Soc. 112, 7077-7079 (1990).

34 Ishikawa, M., Toyoda, E., Ishii, M., Kunai, A., Yamamoto, Y. \& Yamamoto, M. Synthesis of chlorosilanes from (fluoroalkyl)silanes, bis(silyl)benzenes, and .alpha.,.omega.-dihydropolysiloxanes. Organometallics 13, 808-812 (1994).

35 Gao, F., Zhang, L. L., Tang, L. M., Zhang, J., Zhou, Y., Huang, F. R. \& Du, L. Synthesis and properties of arylacetylene resins with siloxane units. Bull. Korean Chem. Soc. 31, 1-5 (2010).

36 Sastri, S. B., Keller, T. M., Jones, K. M. \& Armistead, J. P. Studies on cure chemistry of new acetylenic resins. Macromolecules 26, 6171-6174 (1993).

37 Hergenrother, P. M. \& Smith, J. G. Chemistry and properties of imide oligomers endcapped with phenylethynylphthalic anhydrides. Polymer 35, 4857-4864 (1994).

38 Bindu, R. L., Reghunadhan, C. P. N. \& Ninan, K. N. Addition-cure phenolic resins based on propargyl ether functional novolacs: Synthesis, curing and properties. Polym. Int. 50, 651-658 (2001).

39 Homrighausen, C. L. \& Keller, T. M. High-temperature elastomers from silarylene-siloxanediacetylene linear polymers. J. Polym. Sci. Part A Polym. Chem. 40, 88-94 (2002).

40 Homrighausen, C. L. \& Keller, T. M. Synthesis of hydroxy-terminated, oligomeric poly(silarylene disiloxane)s via rhodium-catalyzed dehydrogenative coupling and their use in the aminosilane-disilanol polymerization reaction. J. Polym. Sci. Part A Polym. Chem. 40, 1334-1341 (2002).

41 Maya, E. M., Snow, A. W. \& Buckley, L. J. Oligodimethylsiloxane linked cyanate ester resins. Macromolecules 35, 460-466 (2002).

42 Gadda, T. M. \& Weber, W. P. Synthesis and characterization of alt-copoly [oligosiloxane/ 1,4-bis(ethylenediphenylsilyl)benzene]s. J. Polym. Sci. Part A Polym. Chem. 44, 4825-4831 (2006)

43 Dvornic, P. R. \& Lenz, R. W. Exactly alternating silarylene-siloxane polymers: 6. Thermal stability and degradation behaviour. Polymer 24, 763-768 (1983). 